\title{
Assimilation and Accommodation
}

\author{
A Systematic Review of the Last Two Decades
}

\author{
Barbara Hanfstingl ${ }^{1} \mathbb{0}$, Ana Arzenšek ${ }^{2}$, Jan Apschner ${ }^{1}$, and Katharina Ingrid Gölly ${ }^{1}$ \\ ${ }^{1}$ Department of Psychology, University of Klagenfurt, Austria \\ ${ }^{2}$ Department of Psychology, University of Primorska, Slovenia
}

\begin{abstract}
This research provides a systematic overview of psychological areas using assimilation and accommodation to explain development and adaptation processes from 1998 to 2018. We primarily aimed to identify the main psychological research areas connected to assimilation and accommodation. We used assimilation and accommodation as keywords to extract data from SpringerLink, PsycINFO, and PsycARTICLES. Of 500 articles, 473 were included in the analysis. Ten categories were identified to allow systematization along with different research areas and development trajectories. The meanings of these terms were analyzed in terms of scientific impact, their connection to Piaget and Baldwin, application, and research methods. Our analysis has distilled the most driving and scientifically relevant approaches to assimilation and accommodation within psychological research, with the work of Baldwin and Piaget influencing practically all views. Thus, we have identified a common understanding of assimilation and accommodation, although the direction of the adaptation process should be made explicit in the future. Based on our analyses, we were able to identify white spots on the research map that should be focused on in future work: the need to better understand the interdependence and synchronicity of both processes, the connection to affects and emotions, and the potential co-research with artificial intelligence.
\end{abstract}

Keywords: assimilation, accommodation, adaptation, Piaget, Baldwin

The concepts of assimilation and accommodation were introduced by Jean Piaget, who extensively applied these in his theory of cognitive development. However, James Mark Baldwin had already used the terms to explain human development in 1906, albeit in a different and even more biological sense related to the reception and processing of information. Baldwin associated assimilation with object recognition, anticipating the concept of over-assimilation, and explained accommodation as follows. Baldwin's definition of assimilation and accommodation shaped the understanding of many later scientists, including Piaget. Baldwin proposed that learning behavior, based on assimilation and accommodation, directly influences natural selection and evolution in an epigenetic sense (named "Baldwin effect"; Simpson, 1953).

Piaget popularized the terms "assimilation," "accommodation," and "equilibration" among the psychological scientific community, despite repeated criticism. Boden remarked that "recent research on development - spanning biology, psychology, and abstract formalization - shows that Piaget was more right than he seemed ... as well as being more wrong" (Boden, 1994, p. XXIX). She comments on the vagueness of Piaget's theoretical statements: "'assimilation' and 'accommodation' have clear meaning in biological contexts. But whether they are equally or - even usefully clear in psychological or epistemological contexts" (Boden, 1994, p. 13).
We suggest that this ambiguity is one reason for the wide application of the concepts in different psychological research contexts, as it allows a degree of freedom in understanding the structure and functioning of developmental and adaptation processes in different psychological contexts, from individual to the system and vice versa. At first glance, it seems that the concepts have evolved into many different understandings, depending on the field of research. In the current integrative review, we aimed to clarify whether such diverse applications can lead to a common understanding, regardless of the domain of application. The review provides a systematic overview of psychological areas where assimilation and accommodation were used to explain development and adaptation processes from 1998 to 2018. It identifies the main psychological research areas where assimilation and accommodation play a pivotal role and clarifies their meanings in different realms.

\section{Data}

We collected data from SpringerLink, PsycINFO, and PsycARTICLES, using "assimilation" and "accommodation" as keywords. We aimed to use general parameters with as few restrictions as possible to obtain various articles with the terms. For SpringerLink, we used the parameters 
"within psychology," "article," and "1998-2018." PsycINFO and PsycARTICLES were combined in one database by $\mathrm{Ovid}^{\circledR}$, where we used the parameters "English language," "peer-reviewed journal," and "1998-2018." The cut-off date was April 17, 2018. We identified 500 contributions (SpringerLink: 130, PsychINFO: 127, PsychARTICLES: 243). After excluding duplicate articles, 473 articles were considered for review.

\section{Categorization}

Our main objective was to identify categories that allow the systematization of assimilation and accommodation along with different research areas and development trajectories. We followed an inductive strategy and searched for specific meanings of the terms, including authors who had developed influential approaches.

After the first reading session, we distilled 11 categories, which mainly represented the final categorization. Following a second reading, we merged some categories because of their content proximity and avoided too many similar categories, such as identity and personality, cultural issues, and more general social issues. We also broadened the psychotherapeutic approach to general clinical issues.

After specifying and describing the categories, we categorized all 473 articles. For clear categorization, a protocol was designed with detailed descriptions of each category, as well as inclusion and exclusion criteria for each category. For all 473 articles, we obtained Cohen's $\kappa=.85$. Based on 62 articles, we tested the reliability with an independent educational psychology researcher and obtained Fleiss' $\kappa=.87$, which, according to Landis and Koch (1977), is nearly perfect. Others, such as MiniTab, Inc. (2020), suggest that a value of at least Fleiss' $\kappa=.75$ indicates a good agreement.

Category overlaps (both clinical and epistemological) occurred at an early stage in some cases, such as for articles on the integration movement in US psychotherapy, which was partially reflected in our data. We decided to include these in the epistemological category, as they mostly contained theoretical discussions of the integration at a methodological level. Here, the key criteria were the main message and target audience of the article. Therefore, in the third reading session, we reviewed each instance of non-compliance with categorization and reassigned these articles to their final respective categories through a joint communicative validation process, which formed the basis for our analyses. We also identified subcategories for each category (see Table E1 in the Electronic Supplementary Material, ESM 1). Piaget is cited in only $99(21 \%)$ articles; 48 articles (10\%) mentioned him, and 318 (67\%) neither mentioned nor cited Piaget.

\section{Text Types and Applied Methods}

We categorized text type and research methodology and identified 10 categories: theoretical, quantitative, qualitative, mixed-method, experimental, quasi-experimental, literature review, systematic review, meta-analysis, and book review. These methods were not randomly distributed across the content categorization. Articles dealing with psycholinguistic topics were mostly experimental or quasiexperimental, and articles with epistemological content were often theoretical contributions. Programming was only found in the category Behavioral Contexts, where authors used the principles of assimilation and accommodation to develop robots capable of learning.

\section{Importance of Assimilation and Accommodation}

We investigated the relevance or impact of the terms assimilation and accommodation in each article, distinguishing between $0=$ no use, only mentioning the terms; 1 = application of an approach; 2 = testing an approach; and 3 = developing a new approach. Most developments were observed under Personality and Identity. Relatively, Behavioral Context, the category with the smallest number of articles, also contained the most developments (Table 1). The Figure in ESM 2 shows the time frame and categories for the use of assimilation and accommodation. ESM 3 provides a list of all articles, sorted by category, year, and first author.

\section{Categories}

\section{Social Context}

The largest, most heterogeneous category contains 104 articles on adapting to a new culture, including national, family, class, and organizational culture. Several articles focused on acculturation models, such as that of Gordon (1964), Berry (1970), and Tajfel (1981). According to Gordon (1964), assimilation is a one-way strategy of adaptation to a new culture, where members of a minority culture adopt dominant cultural attributes (e.g., values, norms, and language) while renouncing their original culture. Gordon described cultural assimilation (1964; in Oyserman et al., 1998, p. 1608) as "adopting the norms of the majority society, while structural assimilation was described as movement of the minority into the social structure of majority society." Social-structural conditions are considered a major obstacle for minorities to be assimilated into the majority society. According to Montalvo (2009), assimilation was standard practice among immigrants adapting to 
Table 1. Importance of assimilation and accommodation per category

\begin{tabular}{|c|c|c|c|c|c|}
\hline Category & No use & $\begin{array}{l}\text { Application of } \\
\text { an approach }\end{array}$ & $\begin{array}{l}\text { Testing an } \\
\text { approach }\end{array}$ & $\begin{array}{c}\text { Developing an } \\
\text { approach }\end{array}$ & Total \\
\hline \multicolumn{6}{|l|}{ Social Context } \\
\hline Count & 64 & 19 & 20 & 1 & 104 \\
\hline$\%$ within category & 61.54 & 18.27 & 19.23 & 0.96 & 100.00 \\
\hline$\%$ of total & 13.53 & 4.02 & 4.23 & 0.21 & 21.99 \\
\hline \multicolumn{6}{|l|}{ Personality and Identity } \\
\hline Count & 20 & 31 & 15 & 7 & 73 \\
\hline \% within category & 27.40 & 42.47 & 20.55 & 9.59 & 100.00 \\
\hline$\%$ of total & 4.23 & 6.55 & 3.17 & 1.48 & 15.43 \\
\hline \multicolumn{6}{|l|}{ Clinical context } \\
\hline Count & 22 & 24 & 12 & 1 & 59 \\
\hline$\%$ within category & 37.29 & 40.68 & 20.34 & 1.69 & 100.00 \\
\hline$\%$ of total & 4.65 & 5.07 & 2.54 & 0.21 & 12.47 \\
\hline \multicolumn{6}{|l|}{ Coping } \\
\hline Count & 10 & 28 & 13 & 1 & 52 \\
\hline$\%$ within category & 19.23 & 53.85 & 25.00 & 1.92 & 100.00 \\
\hline$\%$ of total & 2.11 & 5.91 & 2.75 & 0.21 & 10.99 \\
\hline \multicolumn{6}{|l|}{ Epistemological issues } \\
\hline Count & 18 & 18 & 10 & 6 & 52 \\
\hline$\%$ within category & 34.62 & 34.62 & 19.23 & 11.54 & 100.00 \\
\hline$\%$ of total & 3.81 & 3.81 & 2.11 & 1.27 & 10.99 \\
\hline \multicolumn{6}{|l|}{ Educational context } \\
\hline Count & 23 & 10 & 18 & 0 & 51 \\
\hline$\%$ within category & 45.10 & 19.61 & 35.29 & 0.00 & 100.00 \\
\hline$\%$ of total & 4.86 & 2.11 & 3.81 & 0.00 & 10.78 \\
\hline \multicolumn{6}{|c|}{ Biological and neurophysiological perspectives } \\
\hline Count & 2 & 11 & 8 & 3 & 24 \\
\hline$\%$ within category & 8.33 & 45.83 & 33.33 & 12.50 & 100.00 \\
\hline$\%$ of total & 0.42 & 2.33 & 1.69 & 0.63 & 5.07 \\
\hline \multicolumn{6}{|c|}{ Psycholinguistic approaches } \\
\hline Count & 5 & 3 & 16 & 0 & 24 \\
\hline$\%$ within category & 20.83 & 12.50 & 66.67 & 0.00 & 100.00 \\
\hline$\%$ of total & 1.06 & 0.63 & 3.38 & 0.00 & 5.07 \\
\hline \multicolumn{6}{|l|}{ Behavioral context } \\
\hline Count & 1 & 1 & 1 & 5 & 8 \\
\hline$\%$ within category & 12.50 & 12.50 & 12.50 & 62.50 & 100.00 \\
\hline$\%$ of total & 0.21 & 0.21 & 0.21 & 1.06 & 1.69 \\
\hline \multicolumn{6}{|c|}{ Assimilation and accommodation used in another meaning } \\
\hline Count & 12 & 2 & 0 & 0 & 14 \\
\hline$\%$ within category & 85.71 & 14.29 & 0.00 & 0.00 & 100.00 \\
\hline$\%$ of total & 2.54 & 0.42 & 0.00 & 0.00 & 2.96 \\
\hline \multicolumn{6}{|c|}{ No explicit use of assimilation and accommodation } \\
\hline Count & 12 & 0 & 0 & 0 & 12 \\
\hline$\%$ within category & 100.00 & 0.00 & 0.00 & 0.00 & 100.00 \\
\hline$\%$ of total & 2.54 & 0.00 & 0.00 & 0.00 & 2.54 \\
\hline \multicolumn{6}{|l|}{ Total } \\
\hline Count & 189 & 147 & 113 & 24 & 473 \\
\hline$\%$ within category & 39.96 & 31.08 & 23.89 & 5.07 & 100.00 \\
\hline$\%$ of total & 39.96 & 31.08 & 23.89 & 5.07 & 100.00 \\
\hline
\end{tabular}

Note. Count = Absolute numbers; \% within category = Percentage within a category; Importance of assimilation and accommodation: No use = No explicit or meaningful use of assimilation and accommodation; Application of an approach = for example, a scale, or to explain a phenomenon in the introduction or discussion; Testing an approach = for example, in an experiment, or discussing it, like in an systematic review or theoretical contribution; Developing an approach $=$ contributions, in which newly developed approaches are presented for the first time to the community. 
American culture, gradually losing their native habits and language to be accepted by dominant group members, as it was believed to be the best strategy for the integration of minority status members with the dominant culture.

In their qualitative research, Sonn and Fisher (2003) explored questions of identity and oppression during the apartheid in South Africa. They referred to Tajfel's (1981) understanding of assimilation, stating, "assimilation involves rejecting a minority status in favor of that of the majority, and can include passing, the masking of a true social identity and the appearance of moving into a new group" (p. 118). Both Gordon and Tajfel explain assimilation as a process of abandoning one's own culture and creating a social identity corresponding with the dominant culture.

The accommodation was used more heterogeneously than assimilation. In 22 articles, accommodation was understood as an adjustment of cultural, environmental, linguistic, political, or testing conditions or, vice versa, as a one-way adaptation of certain groups to specific conditions. Young (2010) reports accommodation as adjusting an environment for disabled psychiatric patients, while Moen (2011) discusses the term "work-family fit" in terms of five challenges. Other authors understood accommodation as a two-way process with both sides having to adjust. Cox et al. (2010) understood accommodation as the willingness of the mainstream culture to accept the minority and vice versa. According to Berry's acculturation model, mutual accommodation is a synonym for cultural integration (Berry, 1970, 1997; Berry \& Annis, 1974). This model encompasses four strategies for acculturation: integration, assimilation, separation, and marginalization, which differ in their degree of preservation of original culture and participation in mainstream society. Here, assimilation involves a strong orientation toward mainstream society at the expense of maintaining heritage culture.

A general overview of the articles in this category is provided in Table 1 . Notably, only one article matched our criteria for high scientific impact. Leong and Lee (2006) presented their cultural accommodation model (CAM) for cross-cultural psychotherapy - an extension of Leong's (1996) integrative model of cross-cultural psychotherapy. The authors provide a theoretical model for psychotherapeutic work with clients from different cultures and facing acculturation issues. Within a cultural accommodation process, psychotherapists should identify culturally relevant dimensions (individual or culture-specific constructs, such as individualism-collectivism or high-low context communication styles) that distinguish their culturally diverse clients from mainstream culture. When these cultural blind spots are identified and accommodated, more culturally valid psychotherapeutic interventions can be implemented. CAM, as developed in this article, attracted international interest and received 139 citations by October 2020 . Assimilation was also mentioned in this article as an approach to acculturation, where cultural differences are acknowledged but minimized so that racial and ethnic minority groups are assimilated to the dominant culture.

\section{Personality and Identity}

Personality and Identity included articles that use assimilation and accommodation to describe personality and identity change and development $(N=73)$. One branch can be traced back to Whitbourne's identity theory: "identity is theorized to form an organizing schema through which an individual's experiences are interpreted" (Whitbourne \& Collins, 1998, p. 519). Whitbourne's approach is based on the work of Piaget and Brandtstädter and describes the aging and identity processes and how people deal with them. In this context, Whitbourne and Collins (1998) stress the term "over-assimilation," a fixed perception of a youthful self, ignoring the physical changes experienced with aging. In the clinical context, we found the term "over-accommodation after trauma," (Littleton \& GrillsTaquechel, 2011, p. 421), or an unreachable equilibration (similar to Piaget). Overall, 28 articles dealt with identity formation, of which 13 referred to Whitbourne's identity process theory.

Labouvie-Vief et al. (2007) use assimilation and accommodation to describe processes for integrating affective and cognitive information for further development and link this approach to biologically based emotion theories (Labouvie-Vief, 2015; Panksepp, 2004). Three more approaches from our data explain identity changes through assimilation and accommodation. Bosma and Kunnen (2001) reviewed ego identity, referring to Erikson's theory of psychosocial development and focusing on meaningmaking processes (Kegan, 1994), and was cited only four times in our data. We identified Bosma and Kunnen's work as one of the most influential new approaches in our data since it was cited 669 times by October 2020. In identity formation, cognitive schemata and behavioral scripts function as a framework for assimilating new experiences and information. When assimilation is unsuccessful, a resulting state of dissonance may induce efforts to revise relevant aspects of self-identity (Bosma \& Kunnen, 2001). "Although such [assimilative] processing is quite economical, it can produce theory-ridden distortions of reality. With relatively objective reality monitoring, 'data' from the situation will eventually necessitate accommodative responses" (Bosma \& Kunnen, 2001, p. 54). The approaches presented by Miles et al. (2005) and Kunnen et al. (2008) were not influential of citation impact. 
Seventeen articles highlight personality development, nine of which refer to Block's personality approach (Block, 1982). Block and Block (1980) coined the term "egoresiliency" in the context of ego-control and proposed a new perspective on the understanding of equilibration: assimilation versus accommodation to achieve equilibrium. In this way, interindividual differences in the amount of assimilative and accommodative processes could be investigated. Eight studies applied this approach empirically, using mixed (e.g., Hart et al., 1998), quantitative (e.g., Ying, 2002), or qualitative (Vincent et al., 2015) designs.

Personality and Identity include 12 articles where assimilation and accommodation are used to describe processes occurring when the ego engages with the world, struggles with loss or the finite nature of life, or manages terror. Marrone (1999) relies heavily on assimilation and accommodation in his four-phase model to deal with loss (cognitive restructuring, emotional expression, psychological reintegration, and psychospiritual transformation), describing cognitive assimilation as the integration of the loss of a loved one into existing cognitive schemas, and cognitive accommodation as the creation of new schemas, often accompanied by a cognitive upheaval. In our data, only one article refers to Marrone's model, although it had been cited 237 times by October 2020.

Wortmann and Park (2009) introduced the field of meaning research in our data. They emphasized the role of assimilative and accommodative processes for spirituality and meaning-making when dealing with loss. Park (2010) published an integrative review of meaning-making research and discussed assimilation and accommodation processes in the context of situation reappraisal, referring to Brandtstädter's coping approach (Brandtstädter \& Renner, 1990) and Block (1982). She states that processes, wherein " $[\mathrm{m}]$ eaning making involves changing situational appraised meaning to be more consistent with existing global meaning has been termed assimilation, and that which involves changing global beliefs or goals has been termed accommodation" (Park, 2010, p. 260).

Proulx and Inzlicht (2012) proposed a meaning maintenance model (MMM), based on five A's: retaining a sense of the familiar (Assimilation), restoring a sense of the familiar (Accommodation), returning to the familiar (Affirmation), identifying the familiar (Abstraction), and creating the familiar (Assembly). They associate assimilation with the matching of experiences with existing schemata, and accommodation with a change of schemata.

Seven articles included assimilation and accommodation in relation to personal growth. The two terms were connected with wisdom development (Sternberg, 1998), flow experience (Rathunde, 2010), personal development (Dweck, 2017), the development of imagination (Zittoun
\& Cerchia, 2013), mindfulness (Hugh-Jones et al., 2018), and self-development (Hwang, 2011).

\section{Clinical Context}

The Clinical Context category comprises 59 articles discussing psychotherapeutic and counseling theory and practice. We identified two major groups of articles: 35 articles discussed clinical work issues (e.g., issues in psychotherapy training, psychoanalysis theory, and cognitive processes in processing trauma), and 24 directly addressed issues during psychotherapy sessions (e.g., discussing different psychotherapeutic approaches to trauma, and the client-therapist relationship).

Within our data, only one new approach involving assimilation and accommodation was developed in a clinical context, namely the organismic valuing theory of growth through adversity (Joseph \& Linley, 2005), which has been very influential, with 998 citations as of October 2020. The theory posits that individuals are internally motivated toward growth, and assimilation and accommodation are possible outcomes of cognitive-emotional processing after trauma. Assimilation occurs when existing world models remain unchanged after trauma. When an existing worldview changes for the worse, negative accommodation is experienced. Positive accommodation occurs when existing world models change for the better. This conceptualization closely represents Piaget's view of assimilation and accommodation, though Piaget was neither cited nor mentioned in the article.

Dalgleish (2004, p. 233) discussed the role of schema change during recovery from posttraumatic stress disorder (PTSD). According to Piaget (1962), a slow schema change occurs to the point where existing schemas become untenable as valid representations of the experienced world. At this developmental stage, old schemas are abandoned, and new schemas are instantiated. In line with this view, trauma-related materials will gradually be assimilated into pre-trauma schemas. However, when experiences are significantly inconsistent with existing schemas, schemas need to be reorganized or changed.

Assimilation and accommodation were also discussed in less dominant trauma theories. In Hollon and Garber's cognitive therapy (1988), individuals integrate traumarelated information through assimilation, accommodation, or over-accommodation. This resembles Piaget's conceptualization of assimilation and accommodation; however, Piaget was neither cited nor mentioned.

\section{Coping}

The Coping category contains 52 articles, of which 38 refer to Brandtstädter and Renner's (1990) approach, defining 
assimilation and accommodation as two "complementary modes of coping, (a) transforming developmental circumstances according to personal preferences (assimilative tendency) and (b) adjusting personal preferences to situational constraints (accommodative tendency)" (p. 58). In other words, assimilative coping refers to tenacious goal pursuit, and accommodative coping implies flexible goal adjustment, mostly in the context of aging.

In the last two decades, Brandtstädter and Renner's approach focused on reviews and theoretical and empirical analyses. In their systematic review, Skinner et al. (2003) viewed assimilation in contrast to helplessness and accommodation as inverse to rigid perseverance. Morling and Evered (2006), citing Brandtstädter's approach, conducted a review about secondary control and identified a fit versus control dimension. The fit dimension reflects secondary control in the person-environment fit, whereas control stresses motivation to control the environment. They associated assimilative coping with primary control and accommodative coping with secondary control, suggesting that "secondary control researchers can look to the accommodation literature to find fresh inspiration for theorizing and testing" (Morling \& Evered, 2006, p. 291). Skinner (2007) argued that accommodation is best applied to the fit component of secondary control, suggesting the term "accommodative coping." Brandtstädter also influenced Leipold and Greve (2009), one of the more significant articles in our data (482 citations by October 2020), who present resilience as a conceptual bridge between coping and development and argue that the processes underlying resilience require much more detailed research. They understand assimilation and accommodation to underly coping and self-regulating processes.

Punamäki (1999) reports the most explicit integration of assimilation and accommodation during dreaming. She investigated traumatized children and mood changing processes during dreaming and proposed a model in which dreams function as mood correction, "characterized by a reverse assimilation of incorporating evening mood into dreams and by a direct accommodation of dream content into morning mood" (Punamäki, 1999, p. 213).

\section{Epistemological Issues}

This category contains 52 articles; more than half $(N=28)$ stress integrating different psychotherapeutic schools and their knowledge development. Carpenter (2004) reported Franz Alexander's work from 1963 as anticipating "the assimilation and accommodation of changes in the psychotherapy knowledge base" (Carpenter, 2004, p. 360). Thirteen of our articles refer to Messer's psychodynamic approach of assimilative integration, developed from a postmodern perspective. "Assimilative integration ... consists of incorporating perspectives or practices from other approaches within one's primary theoretical or therapeutic outlook" (Messer, 1992, p. 130). Carere-Comes (1999) suggested accommodative integration to complement Messer's assimilative integration. Wolfe (2008) elaborated this argument and emphasized the need for assimilative and accommodative integration for a unified theory of psychotherapy.

Stricker and Gold (2006), not part of our data, describe four modes of psychotherapy integration: (a) assimilative integration, (b) technical eclecticism, (c) common factors approach, and (d) theoretical integration. There is a preliminary version of this model in our data, and several contributions refer to it, for example, Norcross and Goldfried (2005) and Bradshaw et al. (2011). Assimilative integration has become a fixed component in psychodynamic (Stricker \& Gold, 2019) and cognitive-behavioral (Castonguay et al., 2019) psychotherapy.

Nine articles, sharing similar ideas, explicitly stressed epistemological issues; they were not connected via citations. Carpenter (2005) introduced the so-called First Sight model to examine parapsychological functioning, noting that an unconscious focus on or away from extrasensory contents takes place via assimilation and accommodation. According to Driver-Linn (2003), Kuhn (1970) also defined scientific progress in terms of assimilative and accommodative processes. Walsh and Shapiro (2006), one of the most cited articles in our data (983 citations by October 2020), offer a greater focus on culture beyond psychology and bemoan the focus on assimilation: "The result is an assimilative integration that feeds the global "colonization of the mind' by Western psychology" (Walsh \& Shapiro, 2006, p. 228). Walsh suggests moving from assimilation to accommodation to enrich psychology via pluralism. Another four articles echo these arguments, but not as explicitly (e.g., Teo, 2010).

\section{Educational Context}

This category $(N=51)$ is characterized by frequent citation of Piaget $(N=42)$. No articles presented a completely novel approach; 10 articles reported testing of an approach, and 17 reported applying an approach (Table 1). In 27 articles, assimilation and accommodation were merely mentioned, reflecting relatively low scientific relevance of the terms in this category.

Most articles $(N=23)$ understand assimilation and accommodation as processes of cognitive change by teachers or students. Several reported on the role of assimilation and accommodation in skills development and informal learning, for example, in students' conflict resolution strategies (Güneri \& Çoban, 2004) and learning about violence via video games (Gentile \& Gentile, 2008). Some described 
difficulties in learning processes where the accommodation process was interrupted. For example, Gregoire (2003) described a lack of conceptual change by teachers in teaching science.

In 12 articles, assimilation and accommodation were broadly conceptualized as means of cognitive development in various contexts. Mishra (2014) discussed the cognitive development of children in India according to Piaget's theory of cognitive development, with a profound discussion of the theory's relevance but only a general mention of assimilation and accommodation. Four articles deal with wiki-supported learning. Cress and Kimmerle's (2008) external and internal assimilation and accommodation approach was the basis for these studies, but not part of our data.

\section{Biological and Neurophysiological Perspectives}

Three key topics can be defined from among the 24 articles focusing on the biological context. The first quantitatively significant topic is Fiedler's approach to social cognition, which serves as a theoretical basis for nine articles. The second is memory research ( $N=9$ articles), and the third addresses perception research ( $N=5$ articles).

Renn and Schumer (2013) discussed gene expression plasticity and its loss and defined genetic assimilation as the process by which a phenotype, initially produced in response to a specific environmental stimulus, becomes constitutively expressed over evolutionary time, and thus, independent of the original evoking stimulus. The authors refer to Baldwin (1906) and Crispo (2007), who were not part of our data. However, assimilation and accommodation are part of modern epigenetic research. Based on their ecological perspective on the prefrontal cortex functional development, Werchan and Amso (2017) associate assimilation and accommodation with adaption and niche construction in prefrontal cortex development, requiring a balance between sampling of and specialization in the environment.

Positive mood (or affect) supports assimilation (knowledge-driven), and negative mood (affect) supports accommodation (stimulus-driven) in the context of information processing (Fiedler et al., 2003; Fiedler et al., 2010). In other words, positive affect allows the use of more self-generated stimuli and processes information assimilatively, while negative affect drives us to use more externally provided stimuli and process information accommodatively (see also Experiment 2 in Fiedler et al., 2003). This so-called accommodation-assimilation model is supported in many experiments and studies in our data, for example, in the context of trust research (Lount, 2010; Zhao et al., 2017) and reciprocity of self-disclosure
(Forgas, 2011), in the Zenith study (Simpson et al., 2014), and memory research (Spachtholz \& Kuhbandner, 2017).

Eichenbaum (2016) uses the terms assimilation and accommodation in his research on place cells and the role of the hippocampus in local and semantic memory consolidation. In our data, only Armelin et al. (2017) continued Eichenbaum's research and found that hippocampal assimilation and accommodation influence the development of schemata that are not hippocampus-dependent.

Four articles reported on stress perception research, of which three used the terms in the context of assimilation versus contrast effect. This effect describes a bias where contextual information influences evaluative judgment of stimuli. However, Huber (2008) and Oberfeld and Hecht (2008) only mentioned the assimilation versus contrast effect, whereas Masuda et al. (2008) investigated them in detail in the context of facial emotion perception. Oberfeld and Hecht (2008) found the contrast effect in their experiments on time-to-contact judgments. Smith et al. (2001) use the terms in their research on visual perception and collision control.

\section{Psycholinguistic Approaches}

This category contains 24 articles with relatively high impact. Although no new approaches to assimilation and accommodation were described, 16 articles in this category tested or discussed a new approach (Table 1). Perfetti and Liu's (2005) theory was the dominant approach, as it was tested or discussed in 10 articles. Three articles applied a new approach, and five merely mentioned assimilation and accommodation. Contributions within this category apply assimilation and accommodation for a more detailed understanding of language learning processes.

We grouped articles into two subcategories: the dominant subgroup ( $N=12$ articles) addressed issues in mainly Chinese language learning, using the assimilation and accommodation hypothesis by Perfetti and Liu (2005). Here, assimilation and accommodation are understood analogously to the Piagetian meaning of the terms. During assimilation processes, we use the procedures of our existing language network to acquire a new language. According to this hypothesis, under the condition that native language networks are sufficient for the processing demands of new languages, the L1 system can assimilate an L2 system by applying neural circuits already in place for the native language to process the later acquired one (Zhao et al., 2012, p. 419). Accommodation processes need additional brain regions to adjust to the requirements of a new language (Nelson et al., 2009, p. 810).

The second subcategory was more heterogeneous in content, and primarily comprised articles related to 
psycholinguistics ( $N=9$ articles). Here, assimilation and accommodation were understood as adjustments in language use, for example, when correcting speech errors (e.g., Gormley, 2015), in novel word learning (e.g., Snoeren et al., 2009), or pronunciation changes (e.g., Larraza et al., 2016) when using a dialect.

\section{Behavioral Context}

In recent years, assimilation and accommodation have been explicitly used in a behavioral or computer context. Even though we assigned only eight articles to this heterogeneous category, we consider it significant because five new approaches and visions for future research can be found here.

Masciotra et al. (2001) used assimilation and accommodation to explain how a person acts masterfully in martial arts and thus focus on the behavioral level of assimilation and accommodation. Buisson (2004) presented a computer program that identifies music rhythms via assimilation and accommodation and is the oldest article in our data combining the two processes to facilitate computer learning. Caligiore et al. (2014) apply a brain functional, sensorimotor, and computational perspective, taken from biomedical and electronic engineering, and tested with computer games and humanoid robots. The authors postulate a hierarchical and modular organization of the brain and innovatively define and model assimilation and accommodation (Table 2).

Aguilar and Pérez (2015) introduced the Developmental Engagement-Reflection (Dev E-R) to simulate assimilation and accommodation processes and validated their approach with teachable humanoid robots. Maia and Gonçalves (2015) based their approach to the intellectual development of multi-robot systems (IDeM-MRS) learning formalism on social learning models, using assimilation and accommodation processes as a basis for programming multi-robot systems. These articles, which present pilot studies using assimilation and accommodation, light the way for future research.

\section{Assimilation and Accommodation Used in Another Meaning or Not Explicitly Used}

The final two groups of articles understood assimilation and accommodation heterogeneously and mentioned the terms briefly, broadly, or vaguely, with no scientific relevance of the terms. Regarding the contents, assimilation was analogous to the cognitive model or schema enrichment. Other articles linked assimilation and accommodation to specific phenomena (i.e., brand extension, finding word stems in psychology vocabulary, realizing a true self in Indian tradition, or as a synonym to two intertwined phenomena).

\section{Definitions of Assimilation and Accommodation}

To answer our main question regarding a common meaning for assimilation and accommodation, we compared the most important and influential definitions of the terms. Table 2 provides definitions of assimilation and accommodation in which a new approach was developed or discussed (e.g., Bosma \& Kunnen, 2001; Masciotra et al., 2001), and of articles with a high scientific impact (Brandtstädter \& Renner, 1990; Messer, 1992; Perfetti \& Liu, 2005; Piaget, 1975), or where assimilation and accommodation were integrated into a broader theoretical understanding (Koole et al., 2019) to provide novel definitions of the terms.

Many authors who provided their understandings of assimilation and accommodation referred directly to Piaget (e.g., Aguilar \& Pérez, 2015; Armelin et al., 2017; Buisson, 2004; Caligiore et al., 2014; Carere-Comes, 2001; Castonguay, 2000; Fiedler et al., 2010; Gregoire, 2003; Koole et al., 2019; Labouvie-Vief et al., 2007; Maia \& Gonçalves, 2015; Masciotra et al., 2001; Moskaliuk et al., 2012; Proulx \& Inzlicht, 2012; Spachtholz \& Kuhbandner, 2017; Styła, 2015; Walsh \& Shapiro, 2006). For others, Piaget did not play an explicit role (e.g., Carpenter, 2005; Joseph \& Linley, 2005; Kunnen et al., 2008; Littleton \& Grills-Taquechel, 2011; Marrone, 1999; Miles et al., 2005; Perfetti et al., 2007; Punamäki, 1999; Renn \& Schumer, 2013; Skinner et al., 2003), while Brandtstädter and Renner (1990) explicitly distance themselves from Piaget's definitions. We did not include some articles developing a new approach in Table 2, as they do not provide a clear understanding of assimilation and accommodation or direction of adaptation (e.g., Tao, 2015; Teo, 2010).

\section{Summary and Conclusions}

Since introducing assimilation and accommodation to describe and explain psychological adaptational and developmental processes, the concepts have had a huge impact, especially in understanding (cognitive) development, learning, and social integration processes. To our best knowledge, this is the first systematic overview of the applications and understandings of assimilation and accommodation in the literature. 


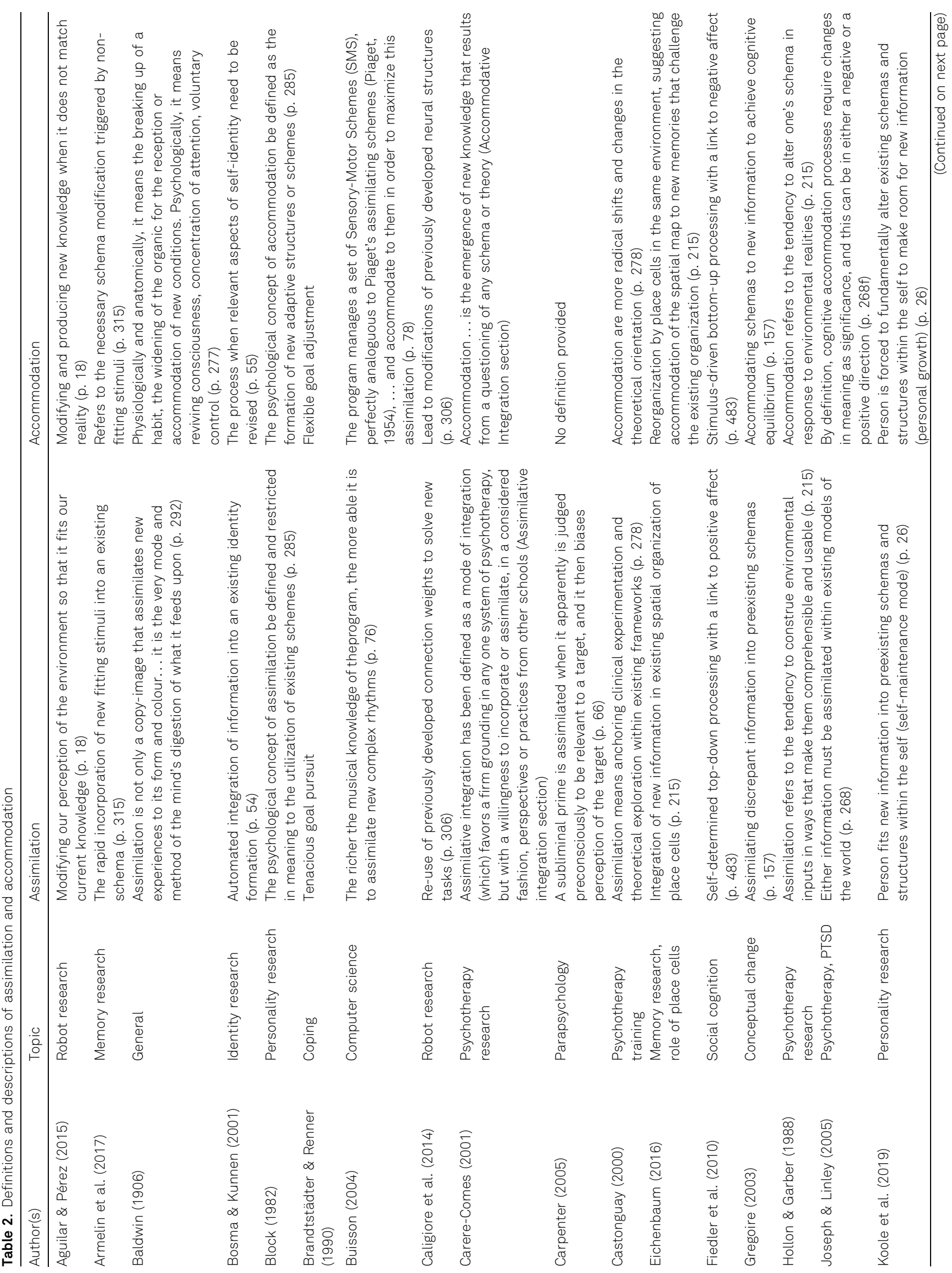




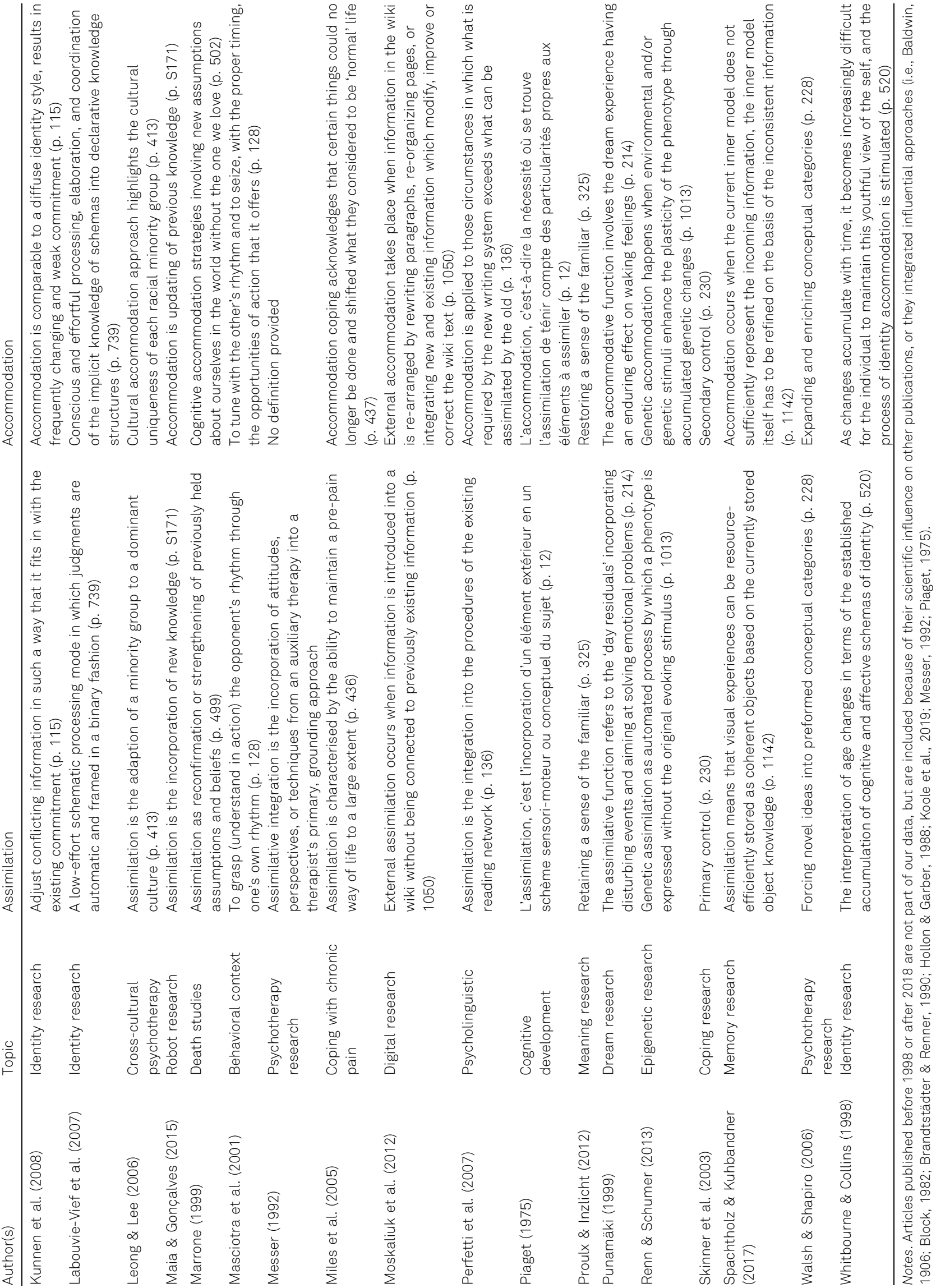


Most articles $(N=104)$ dealt with adaption processes in social issues, with the main question, how to adapt to a new culture, stressing different types of cultures, such as national, family, school, or organizational cultures. Another significant research area dealt with personality and identity $(N=73)$ - identity as more intentional development, and personality as not primarily for conscious developmental processes were distinguished. Many $(N=59)$ emphasized assimilation and accommodation in clinical contexts, be it in trauma research, training therapists, or counseling approaches. Coping research $(N=52)$ is dominated by Brandtstädter's approach $(N=38)$. Epistemological issues $(N=52)$ predominantly include the integration of different psychotherapeutic approaches $(N=28)$. Application of the terms in educational contexts accounted for 51 articles, focusing on specific learning situations and general cognitive development. We identified 24 articles representing biological and neurophysiological perspectives, following three main trajectories: social cognition, memory research, and perception. Psycholinguistic approaches represent $(N=$ $24)$ a more homogenous category. The smallest category ( $N$ $=8$ ) stresses the behavioral context, with promising new developments in robotic learning.

We observed a slight connection between the applied method and the importance of assimilation and accommodation. In the Clinical Context, Educational Context, Epistemological Issues, Personality and Identity, Social Context, Assimilation and Accommodation in Another Meaning, and No Explicit Use of Assimilation and Accommodation categories, most articles were theoretical. Aside from the Clinical Context category, these categories also had the most articles with the lowest impact. Conversely, in the following categories, the terms were empirically tested and discussed in new and propulsive ways: in the Biological and Neurophysiological Perspectives category, most articles adopted an experimental design; in the Coping category, most articles reported on quantitative research; in the Psycholinguistic Approaches category, a quasi-experimental design was prevalent; the most notable articles in terms of developing a new understanding of assimilation and accommodation stemmed where included under Behavioral Context.

\section{Baldwin's Idea and Piaget's Contribution}

Baldwin anticipated epigenetic processes when suggesting that learning behavior based on assimilation and accommodation directly influences natural selection and evolution. Piaget made the terms assimilation, accommodation, and equilibration usable for modern psychological science. Comparing their impact, Piaget's contribution has had an overwhelmingly greater impact on the discipline and seems to be part of the common knowledge. In contrast, Baldwin is cited or mentioned only when his theory contributes specifically to the main message (e.g., Baerveldt, 2013; Wozniak, 2009). This might be because Baldwin mentioned assimilation and accommodation is only a few publications (e.g., Baldwin, 1906), whereas the idea of adaptation via assimilation and accommodation represents the main part of Piaget's work. We conclude that Baldwin's work seems to be underestimated in psychological science. He was already discussing epigenetic processes of evolution (Baldwin effect), confirmed by modern science to closely resemble his initial idea. Piaget's contribution to the study of assimilative and accommodative processes is undoubtedly the highest in psychology and other sciences, and probably the most fruitful.

Some of Baldwin's ideas seem to be attributed to Piaget's work. However, our analysis revealed Piaget's name to be less prominent than expected in scientific publications. We propose two possible reasons for this: that Piaget need not be mentioned whenever assimilation and accommodation are discussed as his contribution is regarded as common knowledge; or that the terms themselves are common knowledge in terms of adaptational processes, and exist without any "founder," as seemingly prevalent in clinical research. In some cases, we regarded the citation of Piaget to be for traditional reasons, for example, to cite the originator of an idea.

\section{New Developments in Assimilation and Accommodation}

In our data, 24 articles presented a new approach to assimilation and accommodation. Most are in the category Personality and Identity $(N=7)$, followed by Epistemological Issues $(N=6)$, Behavioral Context $(N=5)$, Biological and Neurophysiological Perspectives $(N=3)$, Coping, Social Context and Clinical Context (each $N=1$ ). The organismic valuing theory of growth through adversity (Joseph \& Linley, 2005) had the highest impact, with 66 citations per year. The second most cited new approach (43 citations per year) was contributed by Leipold and Greve (2009), who integrated Brandtstädter's coping approach into a resilience theory from a self-regulation perspective. Bosma and Kunnen (2001) were cited 35 times per year and present an identity developmental approach. Some new approaches were not included in our data, but they influenced the publication landscape as they were tested or discussed within our data, such as Perfetti and Liu's (2005) hypothesis of language learning and reading, Bless and Fiedler's approach (1995) to social cognition, or Cress and Kimmerle's (2008) external and internal assimilation and accommodation approach in wiki-supported learning. 


\section{Common Meaning of Assimilation and Accommodation}

We questioned whether a common meaning of assimilation and accommodation can be derived psychologically or whether there should be degrees of freedom in their interpretation. We examined conceptualizations of the terms in the most propulsive articles with newly developed approaches and understandings in our dataset (Table 2). We found a broad generic meaning of assimilation and accommodation, consistent with Baldwin's and Piaget's understanding: "assimilation means integrating environmental information into internal structures and schemas, while accommodation means changing internal structures to meet environmental demands." As shown in Table 2, analog meanings are attributed to assimilation and accommodation, regardless of research focus.

The main question is: Can I change the environment to adapt (assimilation), or do I have to change myself to adapt (accommodation)? Researchers mainly agree that assimilation is a more economical but also more "theory-ridden" and less data-driven process that can distort reality. Accommodation is understood as a stimulus-driven process, more effortful and demanding, and originating from the process of creating new schemas or actualizing existing schemas (e.g., Baldwin, 1906; Brandtstädter \& Renner, 1990; Fiedler et al., 2010; Gregoire, 2003; Hollon \& Garber, 1988; Labouvie-Vief et al., 2007; Marrone, 1999; Morling \& Evered, 2006; Moskaliuk et al., 2012; Nelson et al., 2009; Proulx \& Inzlicht, 2012; Piaget, 1975; Skinner et al., 2003; Walsh \& Shapiro, 2006). As Block (1982) sums it up in a nutshell: "Assimilate if you can; accommodate if you must!” (p. 286).

Sometimes, especially in social and epistemological contexts, the understanding of assimilation and accommodation differs somewhat, though it does not contradict other definitions. Whenever assimilation and accommodation are used to integrate processes in a social context with more than one individual, the meaning of the terms seems to be inverted, and assimilation then refers to the integration of environmental inputs into one's internal structures or schemas. Gordon (1964) and Tajfel (1981), two central sources for many articles in the category Social Context, defined assimilation as the process of abandoning one's own culture and creating a new identity within a dominant culture. Thus, changing myself here means becoming assimilated; if we want to stay in the Piagetian paradigm, we would have to say that the dominant culture assimilates me.

In social, cultural, or epistemological contexts, accommodation is used even more heterogeneously and not always explicitly as a counterpart of assimilation. Young (2010) used accommodation to describe workplaces as adaptable to people from different cultures. Cox et al. (2010) understood assimilation as the opposite of separation and accommodation as the mainstream culture's willingness to accept the minority and vice versa. Leong and Lee (2006) described three different possibilities to deal with different cultures: assimilation, integration, and separation, while Berry (1997) added a fourth called marginalization. Authors who use assimilation and accommodation to explain acculturation processes see assimilation as being assimilated by a dominant culture and understand being accommodative as adaptable to other cultures. This understanding is also shared in the epistemological contribution by Walsh and Shapiro (2006), who speaks of a global "colonization of the mind" by Western psychology (p. 228), and Teo (2010), who focuses on the integration of different epistemological cultures. Some contributors who discuss assimilative versus accommodative integration of different psychotherapeutic schools from a cultural perspective also share this view (e.g., Wolfe, 2001), although not always that clearly (e.g., Stricker \& Gold, 2019).

In summary, we found one difference in understanding assimilation and accommodation, not in the meaning, but the direction of adaptation. Piaget's understanding is used to investigate developmental, learning, and adaptation processes within an individual or between an individual and the (inanimate) environment. The second, almost inverted understanding is used to describe adaptation and acculturation processes between individuals - as a social phenomenon. However, we assume that the understanding is contradictory only at first glance. What is the difference between "I accommodate myself to a dominant culture" and "a dominant culture assimilates me?" The difference is the direction or the perspective from which the process is understood and described. Authors who research the adaptation process of one individual to an inanimate environment see the single individual as the protagonist, so the direction is the same for all who do not consider social processes in their research. As soon as social adaptation processes between different cultures are investigated, the adaption perspective is no longer clear. Most articles that stress this issue in a social context imply the dominant culture to be the protagonist determining the direction of assimilation and accommodation.

If the perspective is unclear, assimilation and accommodation become interchangeable, which means an irreplaceable loss of information and undermines Baldwin's and Piaget's original conceptualizations of adaptation processes. The specificity of assimilation and accommodation is that adaptation does not simply mean adaptation, but they consider the perspective of adaptation on a biological, psychological, and social level. Considering the 
perspective makes the concept one of the most important and systematizing development and adaptation principles in fundamental epistemological assumptions (Hanfstingl, 2019). Future studies should define more explicitly the direction from which adaptation processes are examined (what/who adapts to what/whom). We observed that the perspective of adaption was not always the same or was not explicated, although the two processes should give a clear direction.

\section{Open Questions and Future Research}

Several questions remain. When do individuals assimilate, and when do they accommodate in their interaction with the environment? Many authors state that assimilation is the easy-going knowledge-driven default mode connected to positive affect; when assimilation does not work, the individual starts stimulus-driven accommodation. How do individuals "realize" that it is time to accommodate? Referring to Piaget, Carere-Comes (2001, Introduction) emphasizes that "every assimilation is accompanied by an accommodation". There is a need to understand the interdependence, parallelism, and synchronicity of both processes, and to define specific cut-offs, so to speak, when one process overtakes the other. The most precise ideas in this regard are provided by Piaget (1975); however, these hypotheses have not yet been sufficiently empirically tested. Block's (1982) understanding of equilibration also requires empirical verification.

How are these processes connected to affect? Do they cause affect, are they caused by affect, or are they only accompanied by affect, with no interaction? Which processes run unconsciously and implicitly, and which consciously and explicitly? There are two theoretically unrelated approaches to this question: Fiedler and colleagues (2010) connected assimilation with positive mood (knowledge-driven) and accommodation with negative mood (stimulus-driven), while Labouvie-Vief and colleagues (2007) focused on the integration of emotions into cognitive development through assimilation and accommodation. Their Dynamic Integration Theory posits that cognition and emotion are two aspects of the same system. Although the idea by Fiedler et al. (2010) is integrated by Kazén et al. (2015) into a broader personality theory, the questions remain. The Dynamic Integration Theory potentially explains the integration of emotional and cognitive development on a biological level (e.g., Labouvie-Vief, 2015), also with Panksepp's approach with affective neuroscience (e.g., 2004), but systematic empirical work lacks. Both Labouvie-Vief's and Fiedler's approaches have a high potential to connect it on a theoretical level with research on implicit affect (e.g., Weil et al., 2019), memory research on place cells (Armelin et al., 2017), and research on interoception (e.g., Barrett et al., 2016; Tsakiris \& de Preester, 2019).

Another outstanding issue is the application of assimilative and accommodative processes in artificial intelligence research. Although Boden refers to Piaget's theory as early as 1978 to avoid a psychological vacuum in the development of artificial intelligence, this research is only marginally represented in our data. These developments (Aguilar \& Pérez, 2015; Buisson, 2004; Caligiore et al., 2014; Maia \& Gonçalves, 2015) are not linked to each other, and they currently do not progress beyond pilot development. In databases with a non-psychological focus, artificial intelligence-based on assimilation and accommodation is not the mainstream approach, represented by a few conference presentations (e.g., Kuo \& Cheng, 2010; Zhong et al., 2015). We hypothesize that there is too little knowledge about psychological assimilative and accommodative processes and their biological underpinnings, and computer scientists may not yet deem it appropriate for their own use. Our perspective, however, is that the two fields could benefit greatly from each other, as Boden and the articles in our dataset show.

\section{Limitations}

This research has some limitations. First, datasets were not fully comparable across databases due to different categorizations of the articles in the databases. Although we scrupulously defined keywords and parameters for analysis and prepared a protocol for categorization, we faced difficulties when standardizing our parameters across all databases. Furthermore, we did not analyze contributions in our dataset in terms of their scientific influence; we did not track who cited whom, so there is limited information on the scientific reach of these articles.

Our research scope was limited due to the limitations of the databases used. In databases outside our scope, assimilation and accommodation might be presented differently, and we may have missed important contributions, such as Kazén et al. (2015), who integrated Fiedler's approach to a broader personality theory. We missed this pivotal contribution because the Journal of Personality is not in the three databases we used for our analyses. A similar case is the meaning maintenance model by Heine et al. (2006), on which Proulx and Heine (2010) and Proulx and Inzlicht (2012) base their work. Although not within our scope, these authors contributed immensely to the community and to our current understanding of assimilation and accommodation. 


\section{Electronic Supplementary Materials}

The electronic supplementary materials are available with the online version of the article at https://doi.org/ 10.1027/1016-9040/a000463

ESM 1. Frequencies: Categories and subcategories ESM 2. Importance of assimilation and accommodation by year and category

ESM 3. List of $N=473$ articles analyzed in the systematic review, sorted by category, year, and first author. Additional information: Subcategory assignment, citation frequency, whether Piaget or Baldwin was cited, and on which concept each article was based

\section{References}

Aguilar, W., \& Pérez, R. (2015). Dev E-R: A computational model of early cognitive development as a creative process. Cognitive Systems Research, 33, 17-41. https://doi.org/10.1016/j. cogsys.2014.09.002

Alexander, F. (1963). Fundamentals of psychoanalysis by Franz Alexander. W. W. Norton.

Armelin, A., Heinemann, U., \& de Hoz, L. (2017). The hippocampus influences assimilation and accommodation of schemata that are not hippocampus-dependent. Hippocampus, 27(3), 315-331. https://doi.org/10.1002/hipo.22687

Baerveldt, C. (2013). Constructivism contested: Implications of a genetic perspective in psychology. Integrative Psychological and Behavioral Science, 47(1), 156-166. https://doi.org/10.1007/ s12124-012-9221-z

Baldwin, J. M. (1906). Mental development in the child and the race: Methods and processes. The MacMillan Company.

Barrett, L. F., Quigley, K. S., \& Hamilton, P. (2016). An active inference theory of allostasis and interoception in depression. Philosophical Transactions of the Royal Society of London: Series B, Biological Sciences, 371(1708), 1-17. https://doi.org/ 10.1098/rstb.2016.0011

Berry, J. W. (1970). A functional approach to the relationship between stereotypes and familiarity. Australian Journal of Psychology, 22(1), 29-33. https://doi.org/10.1080/00049537008255207

Berry, J. W. (1997). Immigration, acculturation, and adaptation. Applied Psychology, 46(1), 5-34. https://doi.org/10.1111/ j.1464-0597.1997.tb01087.x

Berry, J. W., \& Annis, R. C. (1974). Acculturative Stress: The role of ecology, culture and differentiation. Journal of CrossCultural Psychology, 5(4), 382-406. https://doi.org/10.1177/ 002202217400500402

Bless, H., \& Fiedler, K. (1995). Affective states and the influence of activated general knowledge. Personality and Social Psychology Bulletin, 21(7), 766-778. https://doi.org/10.1177/ 0146167295217010

Block, J. (1982). Assimilation, accommodation, and the dynamics of personality development. Child Development, 53(2), 281-295. https://doi.org/10.2307/1128971

Block, J. H., \& Block, J. (1980). The role of ego-control and egoresiliency in the organization of behavior. In W. A. Collins (Ed.), Development of cognition, affect, and social relations: Minnesota symposium on child psychology (pp. 39-101). Psychology Press.

Boden, M. A. (1978). Artificial intelligence and Piagetian theory. Synthese, 38(3), 389-414. https://doi.org/10.1007/BF00486637
Boden, M. A. (1994). Piaget. Fontana modern masters (2nd ed.). Fontana Press.

Bosma, H. A., \& Kunnen, E. S. (2001). Determinants and mechanisms in ego identity development: A review and synthesis. Developmental Review, 21(1), 39-66. https://doi.org/ 10.1006/drev.2000.0514

Bradshaw, R. A., Cook, A., \& McDonald, M. J. (2011). Observed and experiential integration (OEI): Discovery and development of a new set of trauma therapy techniques. Journal of Psychotherapy Integration, 21(2), 104-171. https://doi.org/10.1037/a0023966

Brandtstädter, J., \& Renner, G. (1990). Tenacious goal pursuit and flexible goal adjustment: Explication and age-related analysis of assimilative and accommodative strategies of coping. Psychology and Aging, 5(1), 58-67. https://doi.org/10.1037/08827974.5.1.58

Buisson, J. (2004). A rhythm recognition computer program to advocate interactivist perception. Cognitive Science, 28(1), 75-88. https://doi.org/10.1207/s15516709cog2801_3

Caligiore, D., Tommasino, P., Sperati, V., \& Baldassarre, G. (2014). Modular and hierarchical brain organization to understand assimilation, accommodation and their relation to autism in reaching tasks: A developmental robotics hypothesis. Adaptive Behavior, 22(5), 304-329. https://doi.org/10.1177/ 1059712314539710

Carere-Comes, T. (1999). Beyond Psychotherapy: Dialectical Therapy. Journal of Psychotherapy Integration, 9(4), 365-396. https://doi.org/10.1023/A:1023295311832

Carere-Comes, T. (2001). Assimilative and accommodative integration: The basic dialectics. Journal of Psychotherapy Integration, 11(1), 105-115. https://doi.org/10.1023/A:1026633125774

Carpenter, J. T. (2004). Back to the future: F. Alexander (1963) reconsidered. Journal of Psychotherapy Integration, 14(4), 360-370. https://doi.org/10.1037/1053-0479.14.4.360

Carpenter, J. C. (2005). First sight: Part two, elaboration of a model of psi and the mind. Journal of Parapsychology, 69(1), 63-112.

Castonguay, L. G. (2000). A common factors approach to psychotherapy training. Journal of Psychotherapy Integration, 10(3), 263-282. https://doi.org/10.1023/A:1009496929012

Castonguay, L. G., Newman, M. G., \& Holtforth, M. G. (2019). Cognitive-behavioral assimilative integration. In J. C. Norcross \& M. R. Goldfried (Eds.), Handbook of psychotherapy integration (pp. 228-251). Oxford University Press.

Cox, N., Vanden Berghe, W., Dewaele, A., \& Vincke, J. (2010). Acculturation strategies and mental health in gay, lesbian, and bisexual youth. Journal of Youth and Adolescence, 39(10), 1199-1210. https://doi.org/10.1007/s10964-009-9435-7

Cress, U., \& Kimmerle, J. (2008). A systemic and cognitive view on collaborative knowledge building with wikis. International Journal of Computer-Supported Collaborative Learning, 3(2), 105-122. https://doi.org/10.1007/s11412-007-9035-z

Crispo, E. (2007). The Baldwin effect and genetic assimilation: Revisiting two mechanisms of evolutionary change mediated by phenotypic plasticity. Evolution: International Journal of Organic Evolution, 61(11), 2469-2479. https://doi.org/10.1111/ j.1558-5646.2007.00203.x

Dalgleish, T. (2004). Cognitive approaches to posttraumatic stress disorder: The evolution of multirepresentational theorizing. Psychological Bulletin, 130(2), 228-260. https://doi.org/ 10.1037/0033-2909.130.2.228

Driver-Linn, E. (2003). Where is psychology going? Structural fault lines revealed by psychologists' use of Kuhn. American Psychologist, 58(4), 269-278. https://doi.org/10.1037/0003-066X. 58.4.269

Dweck, C. S. (2017). From needs to goals and representations: Foundations for a unified theory of motivation, personality, and 
development. Psychological Review, 124(6), 689-719. https:// doi.org/10.1037/rev0000082

Eichenbaum, H. (2016). Still searching for the engram. Learning and Behavior, 44(3), 209-222. https://doi.org/10.3758/s13420016-0218-1

Fiedler, K., Nickel, S., Asbeck, J., \& Pagel, U. (2003). Mood and the generation effect. Cognition and Emotion, 17(4), 585-608. https://doi.org/10.1080/02699930302301

Fiedler, K., Renn, S.-Y., \& Kareev, Y. (2010). Mood and judgments based on sequential sampling. Journal of Behavioral Decision Making, 23(5), 483-495. https://doi.org/10.1002/ bdm.669

Forgas, J. P. (2011). Affective influences on self-disclosure: Mood effects on the intimacy and reciprocity of disclosing personal information. Journal of Personality and Social Psychology, 100(3), 449-461. https://doi.org/10.1037/a0021129

Gentile, D. A., \& Gentile, J. R. (2008). Violent video games as exemplary teachers: A conceptual analysis. Journal of Youth and Adolescence, 37(2), 127-141. https://doi.org/10.1007/s10964007-9206-2

Gordon, M. M. (1964). Assimilation in American life. Oxford University Press.

Gormley, A. (2015). Acoustic evidence for phonologically mismatched speech errors. Journal of Psycholinguistic Research, 44(2), 105-117. https://doi.org/10.1007/s10936-013-9282-2

Gregoire, M. (2003). Is it a challenge or a threat? A dual-process model of teachers' cognition and appraisal processes during conceptual change. Educational Psychology Review, 15(2), 147-179. https://doi.org/10.1023/A:1023477131081

Güneri, O. Y., \& Coban, R. (2004). The effect of conflict resolution training on Turkish elementary school students: A quasiexperimental investigation. International Journal for the Advancement of Counselling, 26(2), 109-124. https://doi.org/ 10.1023/B:ADCO.0000027425.24225.87

Hanfstingl, B. (2019). Should we say goodbye to latent constructs to overcome replication crisis or should we take into account epistemological considerations? Frontiers in Psychology, 10, Article 1949. https://doi.org/10.3389/fpsyg.2019.01949

Hart, D., Keller, M., Edelstein, W., \& Hofmann, V. (1998). Childhood personality influences on social-cognitive development: A longitudinal study. Journal of Personality and Social Psychology, 74(5), 1278-1289. https://doi.org/10.1037/0022-3514.74.5.1278

Heine, S. J., Proulx, T., \& Vohs, K. D. (2006). The meaning maintenance model: On the coherence of social motivations. Personality and Social Psychology Review, 10(2), 88-110. https://doi.org/10.1207/s15327957pspr1002_1

Hollon, S. D., \& Garber, J. (1988). Cognitive therapy. In L. Y. Abramson (Ed.), Social cognition and clinical psychology: A synthesis (pp. 204-253). Guilford Press.

Huber, D. E. (2008). Immediate priming and cognitive aftereffects. Journal of Experimental Psychology: General, 137(2), 324-347. https://doi.org/10.1037/0096-3445.137.2.324

Hugh-Jones, S., Rose, S., Koutsopoulou, G. Z., \& Simms-Ellis, R. (2018). How is stress reduced by a workplace mindfulness intervention? A qualitative study conceptualising experiences of change. Mindfulness, 9(2), 474-487. https://doi.org/10.1007/ s12671-017-0790-2

Hwang, K.-K. (2011). The Mandala model of self. Psychological Studies, 56(4), 329-334. https://doi.org/10.1007/s12646-0110110-1

Joseph, S., \& Linley, P. A. (2005). Positive adjustment to threatening events: An organismic valuing theory of growth through adversity. Review of General Psychology, 9(3), 262-280. https:// doi.org/10.1037/1089-2680.9.3.262

Kazén, M., Kuhl, J., \& Quirin, M. (2015). Personality interacts with implicit affect to predict performance in analytic versus holistic processing. Journal of Personality, 83(3), 251-261. https://doi. org/10.1111/jopy. 12100

Kegan, R. (1994). In over our heads. Harvard University Press.

Koole, S. L., Schlinkert, C., Maldei, T., \& Baumann, N. (2019). Becoming who you are: An integrative review of self-determination theory and personality systems interactions theory. Journal of Personality, 87(1), 15-36. https://doi.org/10.1111/jopy. 12380

Kuhn, T. S. (1970). The structure of scientific revolutions (2nd ed.). University of Chicago Press.

Kunnen, E. S., Sappa, V., Van Geert, P. L. C., \& Bonica, L. (2008) The shapes of commitment development in emerging adulthood. Journal of Adult Development, 15(3-4), 113-131. https://doi.org/10.1007/s10804-008-9042-y

Kuo, J. Y., \& Cheng, H. K. (2010). Applying assimilation and accommodation for cooperative learning of RoboCup agent. Proceedings of the International Conference on Machine Learning and Cybernetics, 3234-3239. https://doi.org/10.1109/ ICMLC.2010.5580689

Labouvie-Vief, G. (2015). Integrating emotions and cognition throughout the lifespan. Springer.

Labouvie-Vief, G., Diehl, M., Jain, E., \& Zhang, F. (2007). Six-year change in affect optimization and affect complexity across the adult life span: A further examination. Psychology and Aging, 22(4), 738-751. https://doi.org/10.1037/0882-7974.22.4.738

Landis, J. R., \& Koch, G. G. (1977). The measurement of observer agreement for categorical data. Biometrics, 33(1), 159-174. https://doi.org/10.2307/2529310

Larraza, S., Samuel, A. G., \& Oñederra, M. L. (2016). Listening to accented speech in a second language: First language and age of acquisition effects. Journal of Experimental Psychology: Learning, Memory, and Cognition, 42(11), 1774-1797. https:// doi.org/10.1037/xIm0000252

Leipold, B., \& Greve, W. (2009). Resilience. European Psychologist, 14(1), 40-50. https://doi.org/10.1027/1016-9040.14.1.40

Leong, F. T. L. (1996). Toward an integrative model for crosscultural counseling and psychotherapy. Applied and Preventive Psychology, 5(4), 189-209. https://doi.org/10.1016/S09621849(96)80012-6

Leong, F. T., \& Lee, S.-H. (2006). A cultural accommodation model for cross-cultural psychotherapy: Illustrated with the case of Asian Americans. Psychotherapy: Theory, Research, Practice, Training, 43(4), 410-423. https://doi.org/10.1037/0033-3204.43.4.410

Littleton, H. L., \& Grills-Taquechel, A. (2011). Evaluation of an information processing model following sexual assault. Psychological Trauma: Theory, Research, Practice and Policy, 3(4), 421-429. https://doi.org/10.1037/a0021381

Lount, R. B. (2010). The impact of positive mood on trust in interpersonal and intergroup interactions. Journal of Personality and Social Psychology, 98(3), 420-433. https://doi.org/ 10.1037/a0017344

Maia, R. S., \& Gonçalves, L. M. G. (2015). Intellectual development model for multi-robot systems. Journal of Intelligent and Robotic Systems, 80(S1), 165-187. https://doi.org/10.1007/ s10846-015-0224-0

Marrone, R. (1999). Dying, mourning, and spirituality: A psychological perspective. Death Studies, 23(6), 495-519. https://doi. org/10.1080/074811899200858

Masciotra, D., Ackermann, E., \& Roth, W. M. (2001). "Maai”: The art of distancing in Karate-Do mutual attunement in close encounters. Journal of Adult Development, 8(2), 119-132. https://doi.org/10.1023/A:1026498019155

Masuda, T., Ellsworth, P. C., Mesquita, B., Leu, J., Tanida, S., \& van de Veerdonk, E. (2008). Placing the face in context: Cultural differences in the perception of facial emotion. Journal of Personality and Social Psychology, 94(3), 365-381. https://doi. org/10.1037/0022-3514.94.3.365 
Messer, S. B. (1992). A critical examination of belief structures in integrative and eclectic psychotherapy. In J. C. Norcross \& M. R. Goldfried (Eds.), Handbook of psychotherapy integration (pp. 130-165). Basic Books.

Miles, A., Curran, H. V., Pearce, S., \& Allan, L. (2005). Managing constraint: The experience of people with chronic pain. Social Science \& Medicine, 61(2), 431-441. https://doi.org/10.1016/ j.socscimed.2004.11.065

Minitab, Inc. (2020). Kappa statistics for attribute agreement analysis. https://support.minitab.com/en-us/minitab/18/help-andhow-to/quality-and-process-improvement/measurement-systemanalysis/how-to/attribute-agreement-analysis/attributeagreement-analysis/interpret-the-results/all-statistics-andgraphs/kappa-statistics/

Mishra, R. C. (2014). Piagetian studies of cognitive development in India. Psychological Studies, 59(3), 207-222. https://doi.org/ 10.1007/s12646-014-0237-y

Moen, P. (2011). From "work-family" to the "gendered life course" and "fit": Five challenges to the field. Community, Work and Family, 14(1), 81-96. https://doi.org/10.1080/13668803.2010.532661

Montalvo, F. F. (2009). Ethnoracial gap in clinical practice with Latinos. Clinical Social Work Journal, 37(4), 277-286. https:// doi.org/10.1007/s10615-009-0241-1

Morling, B., \& Evered, S. (2006). Secondary control reviewed and defined. Psychological Bulletin, 132(2), 269-296. https://doi. org/10.1037/0033-2909.132.2.269

Moskaliuk, J., Kimmerle, J., \& Cress, U. (2012). Collaborative knowledge building with wikis: The impact of redundancy and polarity. Computers \& Education, 58(4), 1049-1057. https://doi. org/10.1016/j.compedu.2011.11.024

Nelson, J. R., Liu, Y., Fiez, J., \& Perfetti, C. A. (2009). Assimilation and accommodation patterns in ventral occipitotemporal cortex in learning a second writing system. Human Brain Mapping, 30(3), 810-820. https://doi.org/10.1002/hbm.20551

Norcross, J. C., \& Goldfried, M. R. (2005). The future of psychotherapy integration: A roundtable. Journal of Psychotherapy Integration, 15(4), 392-471. https://doi.org/10.1037/1053-0479.15.4.392

Oberfeld, D., \& Hecht, H. (2008). Effects of a moving distractor object on time-to-contact judgments. Journal of Experimental Psychology: Human Perception and Performance, 34(3), 605-623. https://doi.org/10.1037/0096-1523.34.3.605

Oyserman, D., Sakamoto, I., \& Lauffer, A. (1998). Cultural accommodation: Hybridity and the framing of social obligation. Journal of Personality and Social Psychology, 74(6), 1606-1618. https:// doi.org/10.1037/0022-3514.74.6.1606

Panksepp, J. (2004). Affective neuroscience: The foundations of human and animal emotions: Series in affective science. Oxford University Press.

Park, C. L. (2010). Making sense of the meaning literature: An integrative review of meaning making and its effects on adjustment to stressful life events. Psychological Bulletin, 136(2), 257-301. https://doi.org/10.1037/a0018301

Perfetti, C. A., \& Liu, Y. (2005). Orthography to phonology and meaning: Comparisons across and within writing systems. Reading and Writing, 18(3), 193-210. https://doi.org/10.1007/s11145-004-2344-y

Perfetti, C. A., Liu, Y., Fiez, J., Nelson, J., Bolger, D. J., \& Tan, L. H. (2007). Reading in two writing systems: Accommodation and assimilation of the brain's reading network. Bilingualism: Language and Cognition, 10(2), 131-146. https://doi.org/ 10.1017/S1366728907002891

Piaget, J. (1962). Play, dreams, and imitation in childhood. W. W. Norton.

Piaget, J. (1975). L'équilibration des structure cognitives: Problème central du développement [Equilibration of cognitive structures: The central problem of intellectual development]. Presses universitaires de France.
Proulx, T., \& Heine, S. J. (2010). The Frog in Kierkegaard's Beer: Finding Meaning in the Threat-Compensation Literature. Social and Personality Psychology Compass, 4(10), 889-905. https:// doi.org/10.1111/j.1751-9004.2010.00304.x

Proulx, T., \& Inzlicht, M. (2012). The five "A"s of Meaning Maintenance: Finding Meaning in the Theories of SenseMaking. Psychological Inquiry, 23(4), 317-335. https://doi.org/ 10.1080/1047840X.2012.702372

Punamäki, R.-L. (1999). The relationship of dream content and changes in daytime mood in traumatized vs. non-traumatized children. Dreaming, 9(4), 213-233. https://doi.org/10.1023/ A:1021379918556

Rathunde, K. (2010). Experiential wisdom and optimal experience: Interviews with three distinguished lifelong learners. Journal of Adult Development, 17(2), 81-93. https://doi.org/10.1007/ s10804-009-9083-x

Renn, S. C. P., \& Schumer, M. E. (2013). Genetic accommodation and behavioural evolution: Insights from genomic studies. Animal Behaviour, 85(5), 1012-1022. https://doi.org/10.1016/ j.anbehav.2013.02.012

Simpson, E. E., Maylor, E. A., McConville, C., Stewart-Knox, B., Meunier, N., Andriollo-Sanchez, M., Polito, A., Intorre, F., McCormack, J. M., \& Coudray, C. (2014). Mood and cognition in healthy older European adults: The Zenith study. BMC Psychology, 2(1), Article 11. https://doi.org/10.1186/2050-7283-2-11

Simpson, G. G. (1953). The Baldwin effect. Evolution, 7(2), 110-117. https://doi.org/10.1111/j.1558-5646.1953.tb00069.x

Skinner, E. A. (2007). Secondary control critiqued: Is it secondary? Is it control? Comment on Morling and Evered (2006). Psychological Bulletin, 133(6), 911-916; discussion 917-919. https:// doi.org/10.1037/0033-2909.133.6.911

Skinner, E. A., Edge, K., Altman, J., \& Sherwood, H. (2003). Searching for the structure of coping: A review and critique of category systems for classifying ways of coping. Psychological Bulletin, 129(2), 216-269. https://doi.org/10.1037/0033-2909.129.2.216

Smith, M. R. H., Flach, J. M., Dittman, S. M., \& Stanard, T. (2001). Monocular optical constraints on collision control. Journal of Experimental Psychology: Human Perception and Performance, 27(2), 395-410. https://doi.org/10.1037/0096-1523.27.2.395

Snoeren, N. D., Gaskell, M. G., \& Di Betta, A. M. (2009). The perception of assimilation in newly learned novel words. Journal of Experimental Psychology: Learning, Memory, and Cognition, 35(2), 542-549. https://doi.org/10.1037/a0014509

Sonn, C. C., \& Fisher, A. T. (2003). Identity and oppression: Differential responses to an in-between status. American Journal of Community Psychology, 31(1-2), 117-128. https:// doi.org/10.1023/A:1023030805485

Spachtholz, P., \& Kuhbandner, C. (2017). Visual long-term memory is not unitary: Flexible storage of visual information as features or objects as a function of affect. Cognitive, Affective and Behavioral Neuroscience, 17(6), 1141-1150. https://doi.org/ 10.3758/s13415-017-0538-4

Sternberg, R. J. (1998). A balance theory of wisdom. Review of General Psychology, 2(4), 347-365. https://doi.org/10.1037/ 1089-2680.2.4.347

Stricker, G., \& Gold, J. (2019). Assimilative psychodynamic psychotherapy. In J. C. Norcross \& M. R. Goldfried (Eds.), Handbook of psychotherapy integration (pp. 207-227). Oxford University Press.

Stricker, G., \& Gold, J. (2006). An overview of psychotherapy integration. In G. Stricker \& J. R. Gold (Eds.), A Casebook of Psychotherapy Integration (1st ed., pp. 3-16). American Psychological Association.

Styła, R. (2015). Shape of the self-concept clarity change during group psychotherapy predicts the outcome: An empirical validation of the theoretical model of the self-concept change. 
Frontiers in Psychology, 6, Article 1598. https://doi.org/ 10.3389/fpsyg.2015.01598

Tajfel, H. (1981). Human groups and social categories. Cambridge University Press.

Tao, R. (2015). Between physics and metaphysics: Structure as a boundary concept. Integrative Psychological \& Behavioral Science, 49(1), 19-43. https://doi.org/10.1007/s12124-014-9276-0

Teo, T. (2010). Ontology and scientific explanation: Pluralism as an a priori condition of psychology. New Ideas in Psychology, 28(2), 235-243. https://doi.org/10.1016/j.newideapsych.2009. 09.017

Tsakiris, M. \& de Preester, H. (Eds.). (2019). The interoceptive mind: From homeostasis to awareness (1st ed.). Oxford University Press.

Vincent, N., Denson, L., \& Ward, L. (2015). Triggers, timing and type: Exploring developmental readiness and the experience of consciousness transformation in graduates of Australian community leadership programs. Journal of Adult Development, 22(4), 183-205. https://doi.org/10.1007/s10804-015-9211-8

Walsh, R., \& Shapiro, S. L. (2006). The meeting of meditative disciplines and Western psychology: A mutually enriching dialogue. American Psychologist, 61(3), 227-239. https://doi. org/10.1037/0003-066X.61.3.227

Weil, A.-S., Hernández, G. P., Suslow, T., \& Quirin, M. (2019). Implicit affect and autonomous nervous system reactions: A review of research using the Implicit Positive and Negative Affect Test. Frontiers in Psychology, 10, Article 1634. https:// doi.org/10.3389/fpsyg.2019.01634

Werchan, D. M., \& Amso, D. (2017). A novel ecological account of prefrontal cortex functional development. Psychological Review, 124(6), 720-739. https://doi.org/10.1037/rev0000078

Whitbourne, S. K., \& Collins, K. J. (1998). Identity processes and perceptions of physical functioning in adults: Theoretical and clinical implications. Psychotherapy: Theory, Research, Practice, Training, 35(4), 519-530. https://doi.org/10.1037/h0087666

Wolfe, B. E. (2001). A message to assimilative integrationists: It's time to become accommodative integrationists: A commentary. Journal of Psychotherapy Integration, 11(1), 123-131. https:// doi.org/10.1023/A:1026637226683

Wolfe, B. E. (2008). Toward a unified conceptual framework of psychotherapy. Journal of Psychotherapy Integration, 18(3), 292-300. https://doi.org/10.1037/1053-0479.18.3.292

Wortmann, J. H., \& Park, C. L. (2009). Religion/spirituality and change in meaning after bereavement: Qualitative evidence for the meaning making model. Journal of Loss and Trauma, 14(1), 17-34. https://doi.org/10.1080/15325020802173876

Wozniak, R. H. (2009). Consciousness, social heredity, and development: The evolutionary thought of James Mark Baldwin. American Psychologist, 64(2), 93-101. https://doi.org/10.1037/ a0013850

Ying, Y. W. (2002). The effect of cross-cultural living on personality: Assimilation and accommodation among Taiwanese young adults in the United States. American Journal of Orthopsychiatry, 72(3), 362-371. https://doi.org/10.1037/0002-9432.72.3.362

Young, G. (2010). Trends in psychological/psychiatric injury and law: Continuing education, practice comments, recommendations. Psychological Injury and Law, 3(4), 323-355. https://doi. org/10.1007/s12207-010-9092-X

Zhao, J., Li, Q. L., Wang, J. J., Yang, Y., Deng, Y., \& Bi, H. Y. (2012). Neural basis of phonological processing in second language reading: An fMRI study of Chinese regularity effect. Neurolmage, 60(1), 419-425. https://doi.org/10.1016/j.neuroimage.2011.12.074

Zhao, N., Ma, M., \& Zhang, J. (2017). Going beyond the beauty Trust link: The moderating role of mood. Current Psychology, 36(4), 927-935. https://doi.org/10.1007/s12144-016-9481-8

Zhong, C., Songxiang, X., \& Lin, L. (2015). Simulation of the concepts of assimilation, accommodation and equilibration in schema theory based on ART2 network. Proceedings of the
International Conference on Intelligent Human-Machine Systems and Cybernetics, 2, 16-20. https://doi.org/10.1109/ IHMSC. 2015.274

Zittoun, T., \& Cerchia, F. (2013). Imagination as expansion of experience. Integrative Psychological and Behavioral Science, 47(3), 305-324. https://doi.org/10.1007/s12124-013-9234-2

\section{History}

Received September 2, 2020

Revision received July 14, 2021

Accepted August 31, 2021

Published online November 26, 2021

\section{Acknowledgments}

We cordially thank Kristijan Musek Lešnik (University of Primorska), Uroŝ Godnov (University of Primorska), Christian Peter Fritz (University of Klagenfurt), and Derek Firl (University of Klagenfurt) for their support in finalizing the manuscript. Furthermore, we thank Klaus Fiedler for his most helpful comments on prior versions of this manuscript and Alexandra M. Freund for her great support as editor. This work is dedicated to Brigitte A. Rollett, the first author's best teacher and wisest mentor. She teaches that scientific truth is only as good as the scientists behind it, that we can do our best every day, and that we must not lose love and benevolence for humans because we are all humans.

\section{Funding}

The project was funded by the Institute of Instructional and School Development, Alpen-Adria University of Klagenfurt.

\section{ORCID}

Barbara Hanfstingl

(D) https://orcid.org/0000-0002-2458-7585

\section{Barbara Hanfstingl}

Department of Psychology

University of Klagenfurt

Sterneckstrasse 15

9020 Klagenfurt am Woerthersee

Austria

barbara.hanfstingl@aau.at

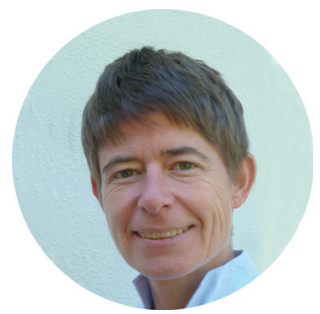

Barbara Hanfstingl is a Psychologist and works as an Associate Professor for Personality Psychology and Educational Psychology at the University of Klagenfurt, Austria. Her research focuses on self-regulation, motivation, and action control and their relation to resilience. Her special interest is directed at epistemological problems of psychology and social sciences.

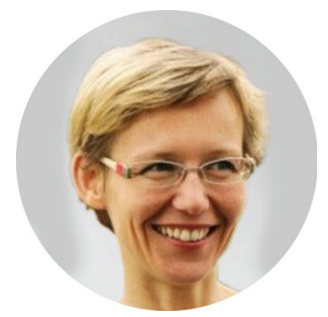

Ana Arzenŝek is a Psychologist and works as an Assistant Professor at the University of Primorska, Slovenia. Her teaching and research areas include work and organizational psychology, leadership, and communication. Her main professional interest is creating positive changes in other people while working on their defense mechanisms. 


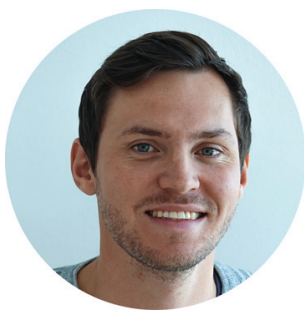

Jan Apschner is an English and Geography teacher and graduated from the University of Klagenfurt, Austria. As a student, he was engaged in the review of the terms assimilation and accommodation. Currently, he works as a Teacher at the Diakonie de la Tour school in Carinthia.

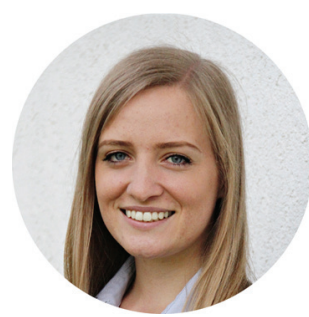

Katharina Ingrid Gölly is a MA student and research assistant at the University of Klagenfurt, Austria. She holds a Bachelor's degree in psychology and in educational sciences. Her research interests are in social psychology, educational psychology, resilience research, and ethical decision-making. 